\title{
Comparative Studies of Oil-Modified Alkyd Resins Synthesized from Epoxidized and Crude Neem Oil
}

\author{
I. R. Jack ${ }^{1}$, A. U. Anya ${ }^{2,}$, O. F. Osagie ${ }^{1}$ \\ ${ }^{1}$ Department of Chemistry, Rivers State University of Science and Technology Port Harcourt, Nigeria \\ ${ }^{2}$ National Research Institute for Chemical Technology (NARICT) Zaria, Nigeria
}

Email address:

anya_214@yahoo.com(A. U. Anya)

${ }^{*}$ Corresponding author

\section{To cite this article:}

I. R. Jack, A. U. Anya, O. F. Osagie. Comparative Studies of Oil-Modified Alkyd Resins Synthesized from Epoxidized and Crude Neem Oil. American Journal of Applied Chemistry. Vol. 4, No. 4, 2016, pp. 120-124. doi: 10.11648/j.ajac.20160404.11

Received: April 3, 2016; Accepted: April 13, 2016; Published: June 18, 2016

\begin{abstract}
Two different alkyd resins; epoxidized neem seed oil-modified alkyd resin (ENOMAR) and crude neem seed oilmodified alkyd resin (CNOMAR) with oil-length of $64.5 \%$ each were synthesized. A portion of neem oil was epoxidized at $50^{\circ} \mathrm{C}$ using per-acid generated in-situ. The (ENOMAR) and (CNOMAR) were prepared using glycolysis and polycondensation methods. Methyl ethyl ketone peroxide (MEKP) and cobalt naphthalate in toluene were employed as the driers. The physicochemical analyses of the synthesized resins were investigated. Also, minimum drying and set to touch time was recorded at $15 \mathrm{hrs}$, $9 \mathrm{hrs}$ and $17 \mathrm{hrs,} 10 \mathrm{hrs}$ for (ENOMAR) and (CMOMAR) respectively at temperature of $120^{\circ} \mathrm{C}$ on exposed for $120 \mathrm{~min}$. Both resins show good resistance in $10 \% \mathrm{HCl}$ and distilled water. (CNOMAR) shows relatively fair resistance in $1 \% \mathrm{NaCl}$ while (ENOMAR) has a poor resistance in the brine solution. FT-IR results shows a broad and sharp peaks at $1732 \mathrm{~cm}^{-1}, 2928 \mathrm{~cm}^{-1}$ and $3465 \mathrm{~cm}^{-1}$ for (ENOMAR) and two broad peaks at $1734 \mathrm{~cm}^{-1}$, and $2927 \mathrm{~cm}^{-1}$ for (CNOMAR). Statistical analysis from ANOVA table comparing the drying time between the two resins gave $F_{v}=0.327$ and $F_{c}=5.990$. Assessments of the properties show that epoxidized neem oil modified alkyd resin (ENOMAR) has better film properties compared to crude neem oil modified alkyd resin (CNOMAR).
\end{abstract}

Keywords: Alkyd resin, Epoxy Functionality, Trans-Esterification, Film Property and Infrared Analysis

\section{Introduction}

Alkyd resins are tough resinous polyester polymer prepared by condensation polymerization of polyhydric alcohol and polybasic acid modified with fatty acid or their glyceride. Alkyd resin was also defined by [5] as the products of poly-condensation reaction between polybasic acid and polyhydric alcohol modified with fatty acid or drying oil. However, it has been reported by [11], where vegetable oil is partially replaced in alkyd synthesis. About $(60-70 \%)$ of an alkyd resin constituents are made-up of biologically derived or biodegradable raw materials and the rest are non biodegradable [4]. Alkyd resin contain some components made up of petroleum based chemical, but are known as a green polymer as reported by [13] The resins contribute about $70 \%$ to the conventional binders used in surface coating. They are used in solvent-based paints and in stoving enamels where they are cross-linked with amino resins. The incorporation of driers (e. g. cobalt naphthenate) causes the alkyd to crosslink in the present of atmospheric oxygen as the solvent evaporates, forming a polymer that is no longer soluble in the original solvent. The aim of the present work is to synthesize alkyd resin with an improved performance quality from neem oil; the increase in demand for vegetable oil with high unsaturated content like linseed oil, cotton seed, soybean oil etc in alkyd resin production necessitated to the need for an alternative. Chemical modification of vegetable oils with low un-saturation will enhance its drying property and improve on the performance quality of the resin synthesized from such oil. Neem oil which is readily available in northern part of Nigeria can be used as a substitute by chemically transforming its existing functional group via epoxidation to enhance its value as a good feedstock in alkyd resin production. Epoxidation of 
neem oil can be carried out with per-acetic acid form in-situ as reported by [8 \& 10]. Epoxy group undergo curing reaction with polybasic acid and other chemicals used in resin modification to produce tough and chemically resistance coatings. The curing process starts with the formation of a hydro-peroxide by the reaction of atmospheric oxygen and carbon-carbon double bond. The produced hydro-peroxides decompose to create alkoxy and hydroxyl free radicals and these free radicals react with each other to form cross-links [2, $7 \&$ 9]. This will change the drying time characteristic and add value to it Assessments of the properties show that epoxidized neem oil modified alkyd resin (ENOMAR) has improved properties compared to crude neem oil modified alkyd resin (CNOMAR).

Table 1. Fatty Acid Percentage Composition of Some Vegetable Oil.

\begin{tabular}{|c|c|c|c|c|c|c|c|c|}
\hline Veg oil & Palmitic & Stearic & Oleic & Linoleic & Linolenic & Other & $\%$ US & $\% \mathrm{~S}$ \\
\hline Rapa seed & 3.5 & 0.9 & 64.1 & 22.5 & 8.0 & 0.0 & 94.6 & 5.4 \\
\hline Soybean & 10.2 & 3.7 & 22.8 & 53.7 & 8.6 & 0.8 & 85.1 & 14.1 \\
\hline Rubber seed & 12. & 5 & 8.3 & 27.8 & 37.7 & 13.4 & 0.1 & 78.9 \\
\hline Cotton seed & 20.1 & 2.6 & 19.2 & 55.2 & 0.6 & 1.2 & 75.0 & 23.8 \\
\hline Jatropha & 15.6 & 10.5 & 42.1 & 30.9 & 0.2 & 0.6 & 73.2 & 26.2 \\
\hline Neem & 18.2 & 20.1 & 41.3 & 16.4 & 0.3 & 2.4 & 58.0 & 39.6 \\
\hline
\end{tabular}

Key; \%US = percentage of un-saturation

$\% \mathrm{~S}=$ percentage of saturation

\section{Materials and Methods}

\subsection{Materials}

The neem seed was obtained and extracted in national research institute for chemical technology (NARICT) Zaria, Kaduna State. Technical grade reagents of hydrogen peroxide, wijs solution, acetic acid, sulphuric acid (98\%), phthalic anhydride, glycerol, styrene, zinc oxide, nitrogen gas and other reagents were all of analytical grade from (BDH). The glassware and equipment used were $500 \mathrm{ml}$ three neck round bottom flask, dean and stark flask, water bath, glass plates, mechanical stirrer, thermometer, reflux condenser, heating mantle, dropping funnel and FTIR-8400S SHIMADZU.

\subsection{Methodology}

\section{Epoxidation of crude neem oil (CNO)}

About $300 \mathrm{~g}$ of $(\mathrm{CNO})$ was introduced into $500 \mathrm{ml}$ three necked round bottom flask fitted with reflux condenser and mechanical stirrer and placed in a water bath. The temperature was regulated to $40^{\circ} \mathrm{C}$ and the flask allowed to stand for $5 \mathrm{~min}$ while stirring at constant speed of 500rpm before adding about $0.1 \%(\mathrm{v} / \mathrm{w})$ concentrated sulphuric acid to oil weight. In a separate flask (conical flask); solution of per-acetic acid was prepared by mixing $14.82 \mathrm{~g}$ of acetic acid and $118.98 \mathrm{~g}$ of hydrogen peroxide. This solution was added drop-wise to the heated neem oil at a constant rate over a period of one hour. The temperature was raised to $55^{\circ} \mathrm{C}$ while still stirring at 500rpm for fine dispersion. This was allowed to stand for $6 \mathrm{hrs}$ while maintaining constant temperature of $55^{\circ} \mathrm{C}$ and stirring speed of 500rpm. During the reaction period, oxirine oxygen content test (OOC) was periodically carried out using AOCS Cd 9-57 test method to ascertain the degree of epoxidation. After having about $85 \%$ of (OOC) test, the reaction was quenched and the mixture transferred to a separating funnel where it was allowed to stand for $24 \mathrm{hr}$. The epoxidized neem oil (ENO) was separated by decanting off the aqueous phase.

\subsection{Synthesis of Alkyd Resin from (ENO) and (CNO)}

Two different resins were prepared from the epoxidized and crude neem oil with each having an oil length of $64.5 \%$. Table 1 and 2 below shows the percentage composition of (ENOMAR) and (CNOMAR) constituents.

Table 2. The Percentage Composition of (ENOMAR) Constituents.

\begin{tabular}{lll}
\hline Raw materials & Weight (gram) & Weight (\%) \\
\hline (ENO) & 300 & 64.5 \\
Phthalic Anhydride & 95 & 20.4 \\
Glycerol & 70 & 15.1 \\
Total & 465 & 100 \\
\hline
\end{tabular}

Table 3. The Percentage Composition of (CNOMAR) Constituents.

\begin{tabular}{lll}
\hline Raw materials & Weight (gram) & Weight (\%) \\
\hline (ENO) & 300 & 64.5 \\
Phthalic Anhydride & 95 & 20.4 \\
Glycerol & 70 & 15.1 \\
Total & 465 & 100 \\
\hline
\end{tabular}

\subsection{Alkyd Resin Preparation}

Stage 1 (alcoholysis):

In this stage, two separate monoglycerides were first prepared from (ENO) and (CNO) one after the other by reacting $300 \mathrm{~g}$ of each oil with $70 \mathrm{~g}$ of glycerol and $0.2 \%$ $\mathrm{NaOH}(\mathrm{w} / \mathrm{w})$ in a reactor equipped with reflux condenser and mechanical stirrer arrangement and nitrogen in-let. This was allowed to stir for 30mins at agitation speed of 800rpm at room temperature in order to help achieve good mixture [14]. The oil was then heated to $250^{\circ} \mathrm{C}$ with agitation speed of (700 rpm) and $\mathrm{N}_{2}$ (nitrogen) with sparging rate of about ( 0 . $\left.05 \mathrm{ft}^{3} / \mathrm{sec}\right)$. The reaction continued until a sample of the reaction mixture became soluble in one to three $(1: 3)$ volumes of anhydrous methanol. After completing the alcoholysis, the reaction mixture was cooled to $140^{\circ} \mathrm{C}$.

Stage 2 (trans-esterification)

In the second stage, $95 \mathrm{~g}$ of phthalic anhydride was added each to the mono-glyceride mixture formed from (ENO) and 
(CNO) produced from the alcoholysis process [6]. The temperature was increased to $250^{\circ} \mathrm{C}$ and maintain at that temperature, while the sparging rate of the $\mathrm{N}_{2}$ was increased to $\left(0.1 \mathrm{ft}^{3} / \mathrm{sec}\right)$. Aliquots were withdrawn to monitor the drop in acid value. The reaction was quenched when the acid value dropped to $13.01 \mathrm{mgKOH} / \mathrm{g}$ and $16.09 \mathrm{mgKOH} / \mathrm{g}$ respectively for epoxidized and crude neem oil modified

alkyd resins. The acid value of aliquots samples taken were determined by titrating with a $0.1 \mathrm{M} \mathrm{KOH}$ solution to the phenolphthalein end point after dissolution in a mixture of toluene and ethanol (1:1) [3].

\section{Results}

Table 4. Physicochemical Properties of Neem Seed Oil.

\begin{tabular}{l|l}
\hline Properties & Values \\
\hline Specific gravity & 0.912 \\
colour & Dark brown \\
Physical state & liquid \\
Acid value & $18.83 \mathrm{mgKOH} / \mathrm{g}$ \\
Saponification value & $173.06 \mathrm{mgKOH} / \mathrm{g}$ \\
Iodine value & $84.69 \mathrm{cg} / \mathrm{g}$ \\
Peroxide Value & $1.42 \mathrm{mg} / \mathrm{g}$ \\
\hline
\end{tabular}

Table 5. Characteristics Properties of the Alkyd Resins Synthesized.

\begin{tabular}{lll}
\hline Properties & (ENOMAR) & (CNOMAR) \\
\hline Acid value $(\mathrm{mgKOH} / \mathrm{g})$ & 13.01 & 16.09 \\
Iodine value $(\mathrm{Cg} / \mathrm{g})$ & 21.15 & 30.63 \\
Refractive index & 1.49 & 1.50 \\
Specific gravity & 0.984 & 0.989 \\
Physical appearance & Dark brown & Very dark brown \\
\hline
\end{tabular}

Table 6. Average Drying and Set to Touch Time of (ENOMAR) and (CNOMAR) @ $80^{\circ} \mathrm{C}$.

\begin{tabular}{lllll}
\hline Time in oven (min) & $\begin{array}{l}\text { (CNOMAR) drying time } \\
\text { (hours) }\end{array}$ & $\begin{array}{l}\text { (ENOMAR) drying time } \\
\text { (hours) }\end{array}$ & $\begin{array}{l}\text { (CNOMAR) set to touch } \\
\text { (hours) }\end{array}$ & $\begin{array}{l}\text { (ENOMAR) set to touch } \\
\text { (hour) }\end{array}$ \\
\hline 30 & 48 & 36 & 20 & 18 \\
60 & 30 & 24 & 18 & 15 \\
90 & 24 & 19 & 15 & 14 \\
120 & 20 & 17 & 13 \\
\hline
\end{tabular}

Table 7. Average Drying and Set to Touch Time of (ENOMAR) and (CNOMAR)@120 C.

\begin{tabular}{lllll}
\hline Time in oven $(\mathbf{m i n})$ & $\begin{array}{l}\text { (CNOMAR) drying time } \\
\text { (hours) }\end{array}$ & $\begin{array}{l}\text { (ENOMAR) drying time } \\
\text { (hours) }\end{array}$ & $\begin{array}{l}\text { (CNOMAR) set to touch } \\
\text { (hours) }\end{array}$ & $\begin{array}{l}\text { ENOMAR) set to touch } \\
\text { (hour) }\end{array}$ \\
\hline 30 & 40 & 32 & 18 & 12 \\
60 & 22 & 13 & 11 \\
90 & 24 & 16 & 11 & 10 \\
120 & 20 & 15 & 10 & 9 \\
\hline
\end{tabular}

Table 8. ANOVA table Comparing the drying time of (ENOMAR) and (CNOMAR) @ $120^{\circ} \mathrm{C}$.

\begin{tabular}{|c|c|c|c|c|c|}
\hline Source & df & Sum of square (SS) & Mean square (MS) & F VALUE & F $_{\text {CRITICAL }}$ \\
\hline Treatment & $2-1=1$ & 31.77 & 31.77 & 0.383 & 5.990 \\
\hline Error sum of square (ESS) & $8-2=6$ & 497.73 & 82.96 & & \\
\hline Total sum (TS) & 7 & 529.50 & & & \\
\hline
\end{tabular}

$\alpha=0.05$, confidence limit $(95 \%)$

Table 9. Chemical Resistance of (ENOMAR) and (CNOMAR) in Different Chemical Environments.

\begin{tabular}{lllll}
\hline Alkyd Type & $\mathbf{1 0 \%} \mathbf{~ H C l}$ & $\mathbf{1 \%} \mathbf{N a O H}$ & $\mathbf{1 0 \%} \mathbf{~ N a C l}$ & Distilled $\mathrm{H}_{2} \mathrm{O}$ \\
\hline (ENOMAR) & Very Good & Poor & Very Good & Very Good \\
(CNOMAR) & Very Good & Fair & Good & Very Good \\
\hline
\end{tabular}

Key;

Very good $=>70 \%$, Good $=60-69 \%$, fair $=50-59 \%$, Poor $=<50 \%$
The performance properties of (ENOMAR) and (CNOMAR) under different chemical environment are given in table 9. In each case, equal amount of the cure film was dipped into the solvent and allow to for stand 6hrs [1]. After which the film is dried and the weight loss measured. Increase in weight loss shows less resistance of the resin to the respective solvent and vice versa. 


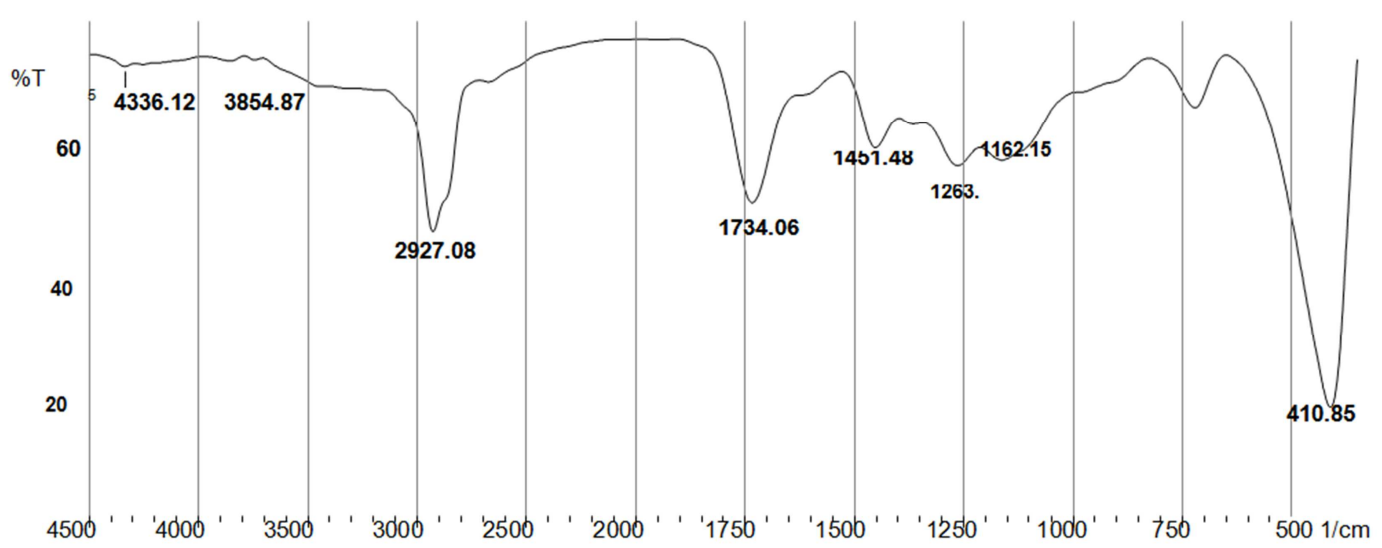

Fig. 1. Infra-red spectra of Epoxidized Neem Oil Modified Alkyd Resin (CNOMAR).

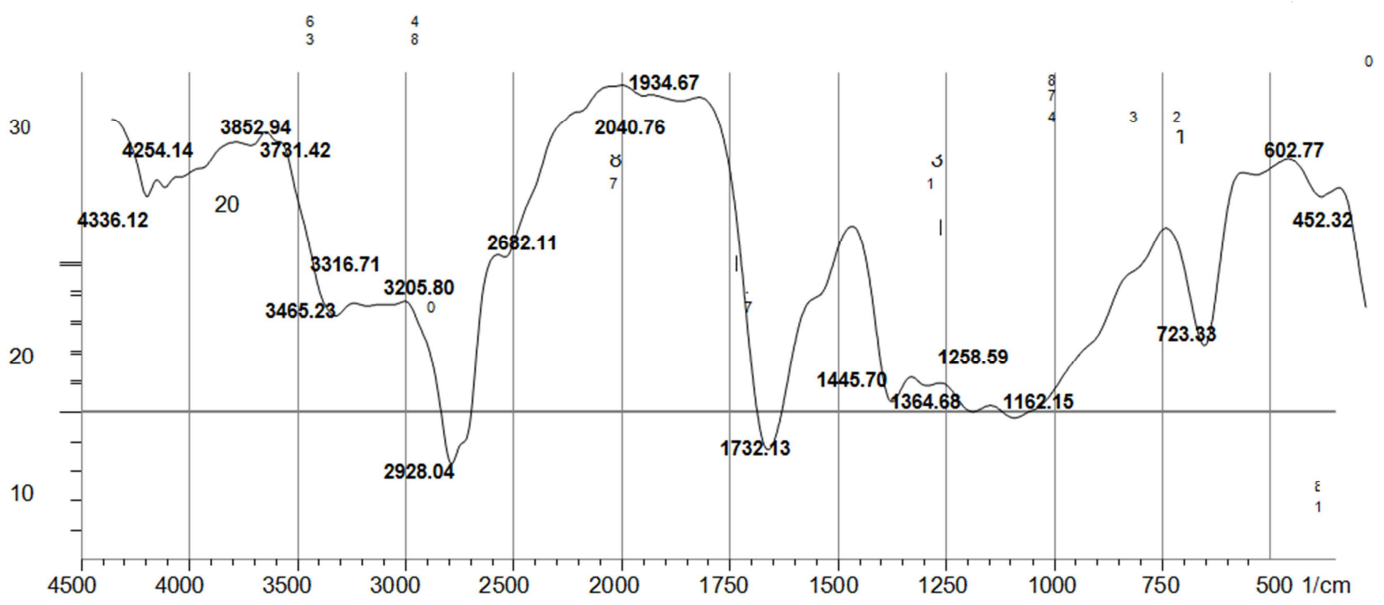

Fig. 2. Infra-red spectra of Epoxidized Neem Oil Modified Alkyd Resin (ENOMAR).

Table 10. Characteristic Peaks in FT-IR Spectra of Alkyd Resins.

Absorption Bands (cm-1) Functional Groups

3466-3477 O-H stretching vibration

2925 Unsaturated C- H stretching vibration

$2856 \mathrm{CH}_{2}$ asymmetric and symmetric vibration

$1731-1733 \mathrm{C}=\mathrm{O}$ stretching vibration

1589-1647 C- $\mathrm{C}$ stretching vibration of $\mathrm{C}=\mathrm{C}$ aliphatic and $\mathrm{C}=\mathrm{C}$ aromatic band

1128-1165 and 1269-1279 C- O- C stretching vibrations attached with

aliphatic and aromatic moiety

983-985 C- C stretching vibration

726-743 C- O- C stretching vibrations attached with aliphatic and aromatic moiety

\section{Discussion}

Minimum acid values of $13.01 \mathrm{mgKOH} / \mathrm{g}$ and $16.09 \mathrm{mgKOH} / \mathrm{g}$ were recorded for (ENOMAR) and (CNOMAR) after reaction time of $150 \mathrm{~min}$. The decrease in acid value from $51.94 \mathrm{mgKOH} / \mathrm{g}$ to $13.01 \mathrm{mgKOH} / \mathrm{g}$ and from $58.69 \mathrm{mgKOH} / \mathrm{g}$ to $16.09 \mathrm{mgKOH} / \mathrm{g}$ for (ENOMAR) and (CNOMAR) respectively may be as a result of the reaction between phthalic anhydride and the monoglyceride to form linear alkyd resin polyester. This implies that as the reaction progresses, the phthalic anhydride is gradually being consumed in the esterification reaction to form polyester. The drying time of (ENOMAR) and (CNOMAR) are listed in tables 6 and 7. The results show that the present of epoxy functional group have improved the curing properties. Increase in temperature from $80^{\circ} \mathrm{C}$ to $120^{\circ} \mathrm{C}$ reduces the drying time of both (ENOMAR) and (CNOMAR), thus enhancing the curing rate. This is attributed to increase in cross-linkages of the polymeric compound initiated by heat. The average lowest drying time was recorded @ $120^{\circ} \mathrm{C}$ when exposed at 120min corresponding to $15 \mathrm{hrs}$ and $17 \mathrm{hrs}$ for (ENOMAR) and (CNOMAR) respectively. While the average lowest set to touch time was recorded @ $120^{\circ} \mathrm{C}$ when expose at a time of $120 \mathrm{~min}$, corresponding to $9 \mathrm{hrs}$ and $10 \mathrm{hrs}$ for (ENOMAR) and (CNOMAR) respectively. This work shows that epoxidized neem oil modified alkyd resin (ENOMAR) shows faster and more curing ability than crude neem oil modified alkyd resin (CNOMAR). The presence of epoxide functional group in (ENOMAR) has aided in reducing its drying time, by decomposing to form peroxy and alkoxy free radicals which then react with each other to form cross-links. Table 8 depicts the statistical analysis result comparing the drying time of (ENOMAR) and (CNOMAR), the result shows that there is a significant different in the drying property between the two resins. The performance properties of the cured (ENOMAR) and (CNOMAR) under different chemical environment are shown in table 10. It was 
found that both (ENOMAR) and (CNOMAR) are highly resistant to $10 \%$ hydrochloric acid (HCL) and distilled water. (ENOMAR) shows relatively poor resistance to alkali $(1 \%$ $\mathrm{NaOH})$ while (CNOMAR) has a fair result in the alkaline solution. The poor resistance to alkaline solution by (ENOMAR) may be attributed to the presence of alkali hydrolysable group. The IR-spectra of (CNOMAR) and (ENOMAR) are shown in fig. $1 \& 2$. The IR spectral of (CNOMAR) depicts the present of carbonyl group $(\mathrm{C}=\mathrm{O})$ at band $1734.06 \mathrm{~cm}^{-1}$, while the strong band at $2927.08 \mathrm{~cm}^{-1}$ is use to represent $(\mathrm{C}=\mathrm{C})$ olefin functionality. IR spectrum of (ENOMAR) in fig. 2 shows small shoulder at $3465.23 \mathrm{~cm}^{1}$, $3316.71 \mathrm{~cm}^{1}$ and $3205.80 \mathrm{~cm}^{-1}$ correspond to free isolated hydroxyl $(\mathrm{O}-\mathrm{H})$ alcohol of the polymer. The strong broad band at $1732.13 \mathrm{~cm}^{-1}$ indicate the presence of carbonyl group $(\mathrm{C}=\mathrm{O})$, while a medium band at $2928.04 \mathrm{~cm}^{-1}$ correspond to the presence of olefins. Comparing the IR spectra of (ENOMAR) and that of (CNOMAR), the result shows that the latter has more functionality resulting from side reactions during cross-linkage.

\section{Conclusion}

The results of this work reveal that alkyd resin with an improved performance quality can be synthesized from neem oil, a non edible vegetable oil with low content of unsaturated fatty acid sourced locally. Chemical modification of the existing functional group in neem oil via epoxidation has aided in changing the drying characteristics by improving the drying property and rate of polymerization. Assessments of the results show that epoxidized neem oil modified alkyd resin (ENOMAR) cures faster and have higher polymerization rate when compared to crude neem oil modified alkyd resin (CNOMAR).

\section{References}

[1] Aigbodion, A. I, and Okieimen F. E (2001). An investigation of the utilization of African locust bean seed oil in preparation of alkyd resins. Nigeria. Ind. Crops Prod. 13, 29-3.

[2] Bat, E., (2005). Synthesis and characterization of hyperbranched and Air Drying Fatty Acid based Resins in Chemical Engineering. Ankara. METU.
[3] Bobalek, E. G, Moor. E. R, Levy. S. S and Lee. C. C (1964). Some implication of gel point concept on the chemistry of alkyd resins. Journal of Applied Polymer Science. 8: 625-657.

[4] Hofland, A., (2012). Alkyd resin down and out to alive and knocking. Progress in Organic coating 73, 274-282.

[5] Ikhuoria. E. U, Aigbodion. A. I and Okieimen. F. E (2004). Enhencing the quality of alkyd resins using methyl ester of rubber seed oil. Tropical Journal of Pharmaceutical Research. 3(1); 311-317.

[6] Ikhuoria. E. U and Aigbodion. A. I (2006). Effect of modification with nitrocellulose and phenol formaldehyde resin on some performance characteristics of rubber seed oil alkyds; African Journal biotechnol, No 19, pp 888-891.

[7] Karakaya, C. (2005). Synthesis of Oil Based Hyper-branched Resins and Their Modification with Melamine Formaldehyde Resins in Chemical Engineering. Ankara. Middle East Technical University.

[8] Mungroo, R., Goud, V. V., Narayan Naik, S., and Dalai, A. K., (2011). Utilization of green seed canola oil for in situ epoxidation. European Journal of Lipid Science and Technology 113(2011)768-774.

[9] Oyman, Z. O., Ming, W., and Linde, R., (2005). Oxidation of drying oils containing non - conjugated and conjugated double bonds catalyzed by a cobalt catalyst. Progress in Organic Coatings. 54 (3): p. 198204.

[10] Petrovic, Z., Zlatanic, A., Lava, C. C., and Sinadinovic-fiser, S., (2002). Epoxidation of soybean oil in toluene with peroacetic and peroxoformic acids- Kinetic and side reactions. European Journal of Lipid Science and Technology (104)293299.

[11] Muralidharan, N, Unnikrishnan. N, Unnikrishnan. K. G (1981). Utilization of rubber seed oil and karinnotta oil for the preparation of air-drying modified alkyd resin. Paintindia 31 (5), 5-9.

[12] Pramanikis. S, Sagak. K, Konwar. B. K, Karak. N. (2012). Synthesis, characterization and properties of a castor oil modified biodegradable poly (ester amide) resin. Prog. Org Coat 75(4), 569-578.

[13] Van H, Oostveen. J, Micciche. E. A, Weijnen. J (2005). Toward sustainability: alkyd resins and alkyd drying agents based on renewable resources. Euro. Coat Journal 16-19.

[14] Ekpa. O. D and Isaac. I. O (2009). Kinetics studies on polyesterification of unsaturated oils \& diacids in alcoholysis process. Research Journal of applied science 4(4)125-128. 